\title{
Biodegradation of high concentrations of halomethanes by a fermentative enrichment culture
}

\author{
Huifeng Shan ${ }^{1}$, Han Wang ${ }^{2}$, Rong Yu ${ }^{2}$, Priya Jacob ${ }^{2}$ and David L Freedman ${ }^{2 *}$
}

\begin{abstract}
A fermentative enrichment culture (designated DHM-1) that grows on corn syrup was evaluated for its ability to cometabolically biodegrade high concentrations of chloroform (CF), carbon tetrachloride (CT), and trichlorofluoromethane (CFC-11). When provided with corn syrup and vitamin $B_{12}\left(0.03\right.$ mol $B_{12}$ per mol CF), DHM-1 grew and biodegraded up to 2,000 mg/L of CF in 180 days, with only minor transient accumulation of dichloromethane and chloromethane. CT (15 mg/L) and CFC-11 (25 mg/L) were also biodegraded without significant accumulation of halomethane daughter products. The rate of CF biodegradation followed a Michaelis-Menten-like pattern with respect to the $B_{12}$ concentration; one-half the maximum rate $(66 \mathrm{mg} C F / L / d)$ occurred at $0.005 \mathrm{~mol} B_{12}$ per mol CF. DHM-1 was able to biodegrade $500 \mathrm{mg} / \mathrm{L}$ of $\mathrm{CF}$ at an inoculum level as low as $10^{-8} \mathrm{mg}$ protein/L. The highest rate of CF biodegradation occurred at pH 7.7; activity decreased substantially below pH 6.0. DHM-1 biodegraded mixtures of CT, CFC-11, and CF, although CFC-11 inhibited CF biodegradation. Evidence for compete defluorination of CFC-11 was obtained based on a fluoride mass balance. Overall, the results suggest that DHM-1 may be effective for bioaugmentation in source zones contaminated with thousands of milligrams per liter of CF and tens of milligrams per liter of CT and CFC-11.
\end{abstract}

Keywords: Chloroform; Carbon tetrachloride; Trichlorofluoromethane; Vitamin $\mathrm{B}_{12}$; Bioremediation

\section{Introduction}

Over the past two decades, substantial progress has been made in use of bioremediation for treating halogenated solvents in groundwater. Nevertheless, in situ bioremediation strategies for groundwater with high concentrations of halogenated methanes such as carbon tetrachloride (CT), chloroform (CF), and trichlorofluoromethane (CFC11) are still lacking. Among these compounds, $\mathrm{CF}$ is often the focal point for evaluating the feasibility of bioremediation because of its high toxicity to most microbes. For instance, inhibition of chlororespiration of chloroethenes by $\mathrm{CF}$ is a concern for sites co-contaminated with $\mathrm{CF}$, and can only be overcome by removing the CF first (Bagley et al. 2000). CF and CT rank highly on the Agency for Toxic Substances and Disease Registry based on their frequency, toxicity, and potential for human exposure at

\footnotetext{
* Correspondence: dfreedm@clemson.edu

${ }^{2}$ Department of Environmental Engineering and Earth Sciences, Clemson University, Box 340919, 29634-0919 Clemson, SC, USA

Full list of author information is available at the end of the article
}

National Priority List sites (ATSDR 2013). Although not ranked by ATSDR, CFC-11 is often a co-contaminant with $\mathrm{CT}$ and CF. For example, approximately $500 \mathrm{mg} / \mathrm{L} \mathrm{CF}$, $26 \mathrm{mg} / \mathrm{L} \mathrm{CFC}-11$ and $10 \mathrm{mg} / \mathrm{L} \mathrm{CT}$ were detected in the source zone at a former industrial site (Shan et al. 2010b). Bioremediation of mixtures of high concentrations of halomethanes is especially challenging.

Most previous research on bioremediation of $\mathrm{CT}$, CF and $\mathrm{CFC}-11$ at elevated concentrations focused on individual compounds. For example, in the presence of vitamin $B_{12}$, a fermentative culture grown on dichloromethane (DCM) transformed up to $270 \mathrm{mg} / \mathrm{L} \mathrm{CF}$ (Becker and Freedman 1994) and a sulfate reducing enrichment culture developed from anaerobic digester sludge transformed up to $350 \mathrm{mg} / \mathrm{L} \mathrm{CT}$ (Freedman et al. 1995). The highest concentration of CFC-11 evaluated previously was $2.2 \mathrm{mg} / \mathrm{L}$ and resulted in accumulation of dichlorofluoromethane (HCFC-21), which is not an acceptable endpoint (Krone and Thauer 1992). Although bioaugmentation 
continues to mature as an option for treatment of chlorinated ethenes (ESTCP 2005), there has been less progress with halogenated methanes. SDC-9 $9^{\text {max }}$ biodegrades CT and $\mathrm{CF}$, but it has been evaluated at relatively low concentrations, i.e., $2.3 \mathrm{mg} / \mathrm{L} \mathrm{CT}$ and $3.2 \mathrm{mg} / \mathrm{L} \mathrm{CF}$ (ESTCP 2005). Recently, Dehalobacter spp. have been described that reductively dechlorinate up to approximately $60 \mathrm{mg} / \mathrm{L}$ of CF to DCM via organohalide respiration (Grostern et al. 2010; Lee et al. 2012). DCM is not an acceptable endpoint, but microbes that use DCM as a sole carbon and energy source have been reported (Freedman and Gossett 1991; Justicia-Leon et al. 2012; Mägli et al. 1998); Lee et al. (2012) described a mixture of Dehalobacter spp. that reduced $50 \mathrm{mg} / \mathrm{L}$ of CF to DCM, which was subsequently fermented to acetate, $\mathrm{CO}_{2}$, and $\mathrm{H}_{2}$; evaluation of higher $\mathrm{CF}$ concentrations was not reported.

In a microcosm study of the abovementioned industrial site, we demonstrated that bioaugmentation is a potentially feasible remediation option for the highest concentration areas of the plume, containing CT, CFC11, and CF (Shan et al. 2010b). Cometabolic biodegradation of the halomethanes was accomplished via addition of a fermentative enrichment culture that grows on corn syrup, along with vitamin $B_{12}$ at a dose of 0.03 mol $B_{12}$ per mol of CT + CFC-11 + CF. Addition of only corn syrup $+\mathrm{B}_{12}$ was also effective, but took twice as long. Accumulation of DCM, chloromethane (CM), HCFC-21, and chlorofluoromethane (HCFC-31) was minor. Following numerous transfers of the culture (designated DHM-1) in mineral salts medium (MSM) amended with corn syrup, $\mathrm{CF}$, and $\mathrm{B}_{12}$, we demonstrated that DHM-1 grows equally well in the presence or absence of $500 \mathrm{mg} / \mathrm{L}$ of CF (Shan et al. 2010a). This was promising from the perspective that bioaugmentation cultures should be able to grow in the presence of the contaminants.

The objectives of this study were to further characterize the DHM-1 enrichment culture with respect to its ability to biodegrade $\mathrm{CF}$ at concentrations up to $4000 \mathrm{mg} / \mathrm{L}, \mathrm{CT}$ $(15 \mathrm{mg} / \mathrm{L})$, and CFC-11 $(25 \mathrm{mg} / \mathrm{L})$, individually and in mixtures; to evaluate the effect of $B_{12}$ dose and inoculum level on the maximum rate of $\mathrm{CF}$ biodegradation; to determine the effect of $\mathrm{pH}$ on the rate of $\mathrm{CF}$ biodegradation, and to evaluate the fate of CFC-11 using a fluoride mass balance.

\section{Materials and methods}

\section{Inoculum, chemicals and MSM}

Experiments were performed with the DHM-1 enrichment culture (ATCC no. PTA-120292) grown on corn syrup (regular type, Sweetener Products Company, Vernon, $\mathrm{CA}$ ) and supplemented with cyanocobalamin (i.e., vitamin $\mathrm{B}_{12}$, USP grade; Research Organics, Inc., Cleveland, $\mathrm{OH}$ ). The bicarbonate-buffered, sulfide-reduced MSM used to grow DHM-1 is described elsewhere (Shan et al. 2010a).
Stock solutions of $\left[{ }^{14} \mathrm{C}\right] \mathrm{CT}$ and $\left[{ }^{14} \mathrm{C}\right] \mathrm{CF}$ were prepared in distilled deionized water at concentrations of approximately $4.5 \mu \mathrm{Ci}$ per $\mathrm{mL}$, using neat $\left[{ }^{14} \mathrm{C}\right] \mathrm{CT}$ $(1.0 \mathrm{mCi} / \mathrm{mmol})$ and $\left[{ }^{14} \mathrm{C}\right] \mathrm{CF}(0.5 \mathrm{mCi} / \mathrm{mmol})$ from American Radiolabeled Chemicals, Inc. (Saint Louis, MO). CT (99.9\%, Sigma-Aldrich, Saint Louis, MO), CF (99.7\%, Sigma-Aldrich), DCM (99.9\%, AlliedSignal, Morristown, NJ), CFC-11 (99\%, Sigma-Aldrich), and carbon disulfide $\left(\mathrm{CS}_{2}, 100 \%\right.$, J.T. Baker, Center Valley, PA) were obtained as neat liquids. CM (99.9\%, Praxair, Danbury, CT), HCFC21 (dichlorofluoromethane, 99\%, SynQuest Labs, Alachua, FL), HCFC-31 (chlorofluoromethane, 99\%, SynQuest Labs), and methane (99.99\%, Matheson, Longmont, CO) were obtained as neat gases. All other chemicals used were reagent grade.

\section{Transformation of individual halomethanes}

The ability of the DHM-1 enrichment culture to biodegrade individual halomethanes $(\sim 15 \mathrm{mg} / \mathrm{L} \mathrm{CT}, 25 \mathrm{mg} / \mathrm{L}$ CFC-11, or $500-4000 \mathrm{mg} / \mathrm{L}$ CF) was evaluated with an initial inoculum of $2.5-5.0 \mathrm{mg} / \mathrm{L}$ protein (except in experiments that evaluated lower inoculum levels). Treatments were prepared with $B_{12}(0.03 \mathrm{~mol}$ per mol of halomethane, except in experiments that evaluated lower inoculum levels), and without $\mathrm{B}_{12}$, in $160 \mathrm{~mL}$ serum glass bottles with $100 \mathrm{~mL}$ of MSM, in an anaerobic chamber (Coy Laboratory Products, Inc.) containing an atmosphere of approximately $98 \% \mathrm{~N}_{2}$ and $2 \% \mathrm{H}_{2}$. The initial dose of corn syrup was $900 \mathrm{mg} / \mathrm{L}$ ( 960 mg/L as chemical oxygen demand) (Shan et al. 2010a). After purging the headspace with $30 \% \mathrm{CO}_{2} / 70 \% \mathrm{~N}_{2}$ for $1 \mathrm{~min}$, the bottles were sealed with 20-mm Teflon-faced red rubber septa and aluminum crimp caps. $\left[{ }^{14} \mathrm{C}\right] \mathrm{CT}$ and $\left[{ }^{14} \mathrm{C}\right] \mathrm{CF}$ were purified on a gas chromatograph prior to addition to the serum bottles to provide an initial ${ }^{14} \mathrm{C}$ activity of $0.45 \mu \mathrm{Ci} /$ bottle, as previously described (Shan et al. 2010a). The fate of CFC-11 was assessed based on release of fluoride instead of using $\left[{ }^{14} \mathrm{C}\right] \mathrm{CFC}-11$, which was prohibitively expensive.

Non-labeled CF, CT and CFC-11 were added using neat compounds. Media controls (no substrate, no culture) with and without $B_{12}$ were prepared for each halomethane. The bottles were incubated quiescently in an inverted position at room temperature $\left(22-24^{\circ} \mathrm{C}\right)$ in the anaerobic chamber. $\mathrm{pH}$ was monitored weekly and maintained between 6.7-7.7. Decreases in $\mathrm{pH}$ indicated that the corn syrup was undergoing fermentation; when decreases in $\mathrm{pH}$ stopped, a second dose of corn syrup was added.

The highest concentration of CF tested with DHM-1 in previous investigations was $500 \mathrm{mg} / \mathrm{L}$ (Shan et al. 2010a). Experiments in this study evaluated CF concentrations of 1000, 2000, and $4000 \mathrm{mg} / \mathrm{L}$. Serum bottles were prepared as described above, except that only unlabeled CF was added. Most experiments included water 
controls (WC), consisting of $100 \mathrm{~mL}$ of distilled deionized water and CF, CT, and CFC-11.

\section{Effect of $B_{12}$ concentration and DHM-1 inoculum}

The effect of vitamin $B_{12}$ concentration on CF transformation rates by DHM-1 was evaluated in serum bottles as described above, except that the concentration of $\mathrm{B}_{12}$ was varied from 0.0 to $0.03 \mathrm{~mol} \mathrm{~B}_{12}$ per mol of $\mathrm{CF}$ added (500 $\mathrm{mg} \mathrm{CF} / \mathrm{L}=4.19 \mathrm{mM}$ ), only one dose of corn syrup was added, and the bottles were continuously mixed on a shaker table. Media controls were included to evaluate abiotic losses of CF. The highest CF biodegradation rate for a given $B_{12}$ dose was determined by linear regression of $\mathrm{CF}$ concentration versus time. The results for all $\mathrm{B}_{12}$ doses were fit (using Matlab, version 7.10.0) to a modified form of the Michaelis-Menten model:

$$
V=\frac{V \max \cdot \frac{B_{12}}{C_{0}}}{\frac{B_{12}}{K_{M}}+\frac{B_{12}}{C_{0}}}
$$

where $V=$ rate of CF biodegradation $(\mathrm{mg} / \mathrm{L} / \mathrm{d}) ; V_{\max }=$ maximum rate of $\mathrm{CF}$ biodegradation $(\mathrm{mg} / \mathrm{L} / \mathrm{d}) ; B_{12} / C_{o}=$ molar concentration of $\mathrm{B}_{12}$ added, divided by the molar concentration of CF added; and $B_{12} / K_{M}=$ molar ratio at which $V$ is one half of $V_{\max }$.

The effect of DHM-1 inoculum concentration on the CF biodegradation rate was evaluated using 10 treatments. Half of the treatments received varying inoculum levels of DHM1; the others consisted of abiotic controls. Treatments were prepared in the same manner described in the section for transformation of individual halomethanes, with an initial $\mathrm{CF}$ addition of approximately $500 \mathrm{mg} / \mathrm{L}$ (without $\left[{ }^{14} \mathrm{C}\right] \mathrm{CF}$ ).

\section{Effect of $\mathrm{pH}$}

Biodegradation rates for $500 \mathrm{mg} / \mathrm{L}$ of CF by DHM- 1 were measured at $\mathrm{pH}$ levels from 5.0 to 7.7 . $\mathrm{B}_{12}\left(0.03 \mathrm{~mol} \mathrm{~B}_{12}\right.$ per mol of CF added) and corn syrup (900 $\mathrm{mg} / \mathrm{L}$ ) were added to all treatments. Serum bottles were prepared as described above for the $\mathrm{B}_{12}$ dose experiment, with the following modifications. The MSM was prepared at the target $\mathrm{pH}$ by varying the amounts of $\mathrm{K}_{2} \mathrm{HPO}_{4}$ and $\mathrm{KH}_{2} \mathrm{PO}_{4}$. After adding sodium sulfide, the final $\mathrm{pH}$ was adjusted using either $\mathrm{H}_{3} \mathrm{PO}_{4}(1 \mathrm{M})$ or $\mathrm{NaOH}(8 \mathrm{M})$; the MSM was incubated for six days to ensure equilibrium was reached at the target $\mathrm{pH}$, before inoculating the DHM-1 enrichment culture $(5 \% \mathrm{v} / \mathrm{v})$. It was not necessary to sparge the headspace of the bottles with $30 \% \mathrm{CO}_{2} / 70 \% \mathrm{~N}_{2}$. Each time $\mathrm{CF}$ was analyzed on the gas chromatograph, the $\mathrm{pH}$ was measured ( $0.2 \mathrm{~mL}$ sample) and, as needed, increased back to the target level using $\mathrm{NaOH}(8 \mathrm{M})$; decreases in $\mathrm{pH}$ were caused by fermentation of the corn syrup to organic acids. The highest $\mathrm{CF}$ biodegradation rate at a given $\mathrm{pH}$ was determined in the same manner described above for varying $B_{12}$ doses. Lag times were based on the time from day zero to the first data point used to determine the highest biodegradation rate.

\section{Transformation of mixtures of halomethanes}

The ability of DHM-1 to biodegrade mixtures of CT, CF, and CFC-11 was evaluated in mixtures of two or three compounds. With two compounds, a single dose of $\mathrm{B}_{12}$ was provided at the start $\left(0.03 \mathrm{~mol} \mathrm{~B}_{12}\right.$ per mol of total halomethanes added). When all of the halomethanes were present, $B_{12}$ was added in a stepwise manner, i.e., the first dose of $B_{12}$ was made based on the initial moles of CT; when CT transformation was nearly complete, a second dose of $B_{12}$ was made based on the initial moles of CFC-11, and when CFC-11 was nearly consumed, a third dose was added based on the initial moles of CF. Along with the second dose of $B_{12}$, the bottles were reinoculated with DHM-1 (i.e., another $5 \mu \mathrm{g}$ protein per $\mathrm{mL}$ ), based on preliminary tests that indicated the culture's activity on CFC-11 and CF diminished after completing transformation of $\mathrm{CT}$, presumably because $\mathrm{CT}$ transformation yields inhibitory intermediates (Lewis et al. 2001). Controls with CT, CF and CFC-11 present included $\mathrm{MSM}+\mathrm{B}_{12}$ added (but not inoculated), autoclaved (AC; inoculated with DHM-1 in MSM and then autoclaved for $1 \mathrm{~h}$ ), and water only.

\section{Analytical methods and ${ }^{14} \mathrm{C}$ distribution}

The amounts of CT, CFC-11, CF, DCM, CM, HCFC-21, HCFC-31, methane and $\mathrm{CS}_{2}$ present in serum bottles were determined by analysis of headspace samples using a gas chromatographic method (Shan et al. 2010a, b). Aqueous phase concentrations were calculated using Henry's Law constants (Shan et al. 2010a, b). Fluoride was measured by ion chromatography (details in Additional file 1). The amount of ${ }^{14} \mathrm{C}$ activity and its distribution in the gas phase (quantified using gas chromatography followed by combustion) and liquid phase were determined as previously described (Shan et al. 2010a, b). Protein concentration was measured with a $\mathrm{BCA}^{\text {twx }}$ protein assay kit (Pierce Chemical Company) by following the manufacturer's enhanced protocol after lysing the cells (Coleman et al. 2002).

\section{Results}

\section{Transformation of individual halomethanes}

When provided with corn syrup and $\mathrm{B}_{12}$, DHM-1 readily biodegraded CT, CFC-11, and CF (Figure 1). Average transformation rates [i.e., (initial concentration)/(time to reach the detection limit)] were $1.3,0.54$, and $22 \mathrm{mg} / \mathrm{L} / \mathrm{d}$ for CT, CFC-11, and CF, respectively. Reductive dehalogenation products (i.e., CF, DCM and CM from CT; HCFC-21 from CFC-11; and DCM and CM from CF) at the end of the incubation period represented $6 \%$ or less 


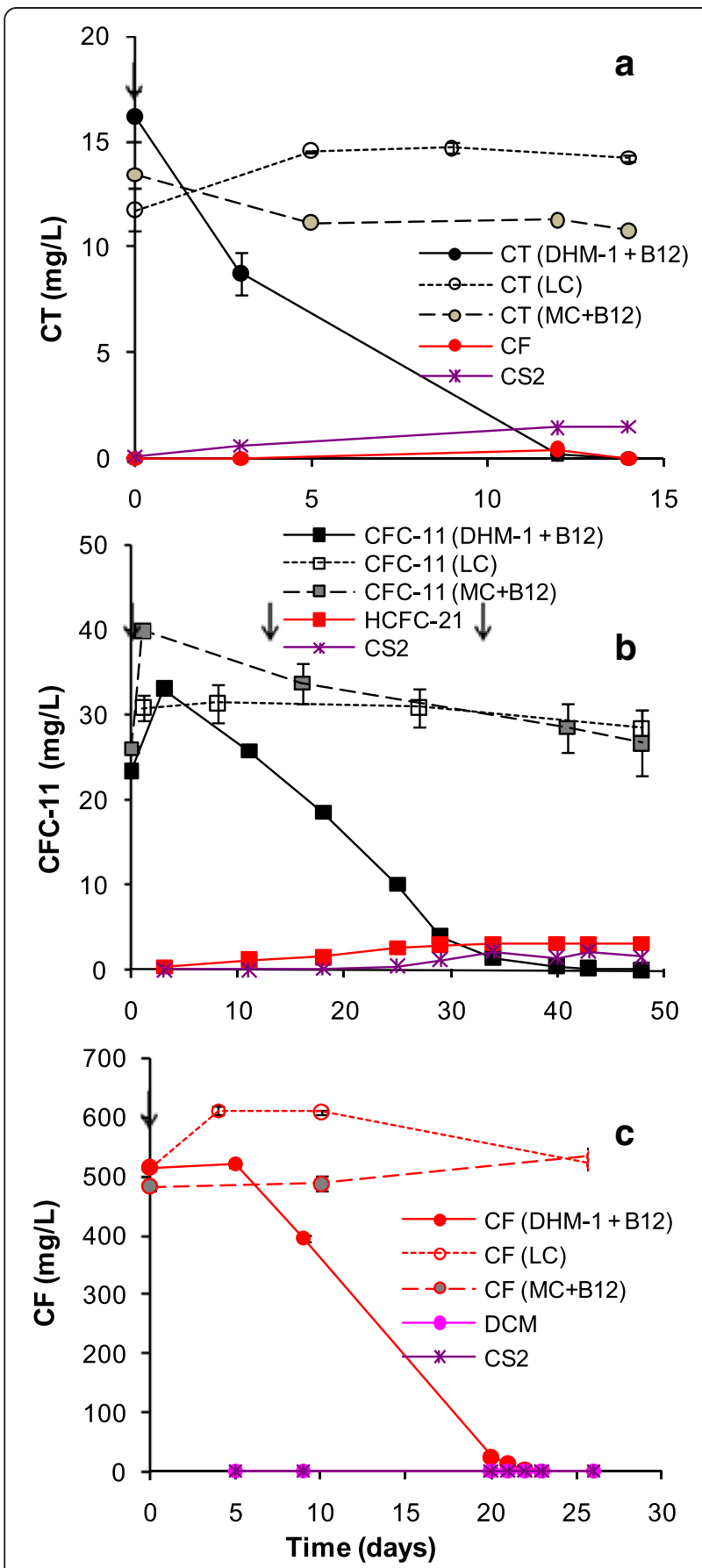

Figure 1 Transformation of (a) CT; (b) CFC-11; and (c) CF, by DHM-1 in MSM with corn syrup and $B_{12}$ added. $L C=$ live control (DHM-1 with corn syrup but without $\mathrm{B}_{12}$ ); $\mathrm{MC}+\mathrm{B}_{12}=$ media control with $B_{12}$. Daughter products are shown only for the DHM-1 $+B_{12}$ treatments. $\downarrow=$ addition of corn syrup; $B_{12}$ was added only at $t=0$. Error bars are the data range for duplicate bottles; when not visible, the bars are smaller than the symbols. The initial increase in CFC-11 was likely due to insufficient time to establish equilibrium at time zero between the headspace and liquid phases. of CFC-11 and $1 \%$ percent of CT and CF. $\mathrm{CS}_{2}$ accounted for $5-16 \%$ of the CT consumed, indicating a substitutive pathway was involved. Over a 14 day period, approximately $20 \%$ of the initial CT was consumed in the media $+\mathrm{B}_{12}$ treatment. No losses occurred in the live control (i.e., DHM-1 with corn syrup but without $B_{12}$ ) or in media without $B_{12}$ (Additional file 1: Figure S1), indicating that abiotic transformation of CT in MSM was mediated by $\mathrm{B}_{12}$. Biotransformation of CFC-11 started after a lag of approximately 10 days and was complete by day 48 (Figure 1b). Approximately equal amounts of HCFC-21 and $\mathrm{CS}_{2}$ (i.e., $3 \mu \mathrm{mol} /$ bottle each) accumulated, while formation of HCFC-31 was negligible. Only a minor amount of CFC-11 transformation occurred in the live control and media $+\mathrm{B}_{12}$ control. No transformation of CFC-11 occurred in the MSM control without $\mathrm{B}_{12}$ (Additional file 1: Figure S1). Biotransformation of CF $(513 \mathrm{mg} / \mathrm{L})$ occurred only in the live treatment with DHM-1, corn syrup, and $B_{12}$; none was observed in the live control, media $+B_{12}$ control, or in the media without $\mathrm{B}_{12}$ control (Additional file 1: Figure S1). Methane formation was absent in all treatments.

${ }^{14} \mathrm{CO}$ and ${ }^{14} \mathrm{CO}_{2}$ were the dominant products from transformation of $\left[{ }^{14} \mathrm{C}\right] \mathrm{CT}$ and $\left[{ }^{14} \mathrm{C}\right] \mathrm{CF}$ (Table 1). The sum of $\mathrm{CO}$ and $\mathrm{CO}_{2}$ accounted for approximately $70 \%$ of $\mathrm{CT}$ or $\mathrm{CF}$ transformation. $\mathrm{CO}_{2}$ predominated from $\mathrm{CT}$ transformation (i.e., over $50 \%$ ) while $\mathrm{CO}$ was predominant from CF transformation. Only a minor amount of $\mathrm{CS}_{2}$ accumulated from CT transformation (i.e., 5.2\%). Soluble compounds were the third most significant ${ }^{14} \mathrm{C}$ labeled product. High performance liquid chromatographic analysis indicated that the main products were formate (35-36\%) and propionate (14-23\%) (Additional file 1: Table S1). Synthesis of propionate from $\mathrm{CO}_{2}$ has been observed previously, via pathways speculated to include a reversal of syntrophic propionate degradation or reductive formation from $\mathrm{H}_{2}+\mathrm{CO}_{2}$ in combination with homoacetogenesis (Conrad and Klose 1999).

A mass balance for fluoride release during biodegradation of CFC- 11 by the DHM- 1 enrichment culture was evaluated. In the presence of corn syrup and $B_{12}$, the average fluoride recovery was $99.5 \%$ (Table 2). This takes into account the fluoride that resided in the minor amount of HCFC-21 and HCFC-31. Thus, nearly all of the CFC-11 consumed by DHM-1 in the presence of corn syrup and $B_{12}$ resulted in stoichiometric release of fluoride. The increase in fluoride coincided with consumption of CFC-11 (Additional file 1: Figure S2). Fluoride was also detected in the abiotic control containing MSM and $B_{12}$, although only $44 \%$ as much CFC- 11 was degraded and the percent recovery for fluoride was not as high. There was no significant consumption of CFC-11 or release of fluoride in the treatments without $\mathrm{B}_{12}$ added. 
Table 1 Products from biodegradation of $\left[{ }^{14} \mathrm{C}\right] \mathrm{CT}$ and $\left[{ }^{14} \mathrm{C}\right] \mathrm{CF}$ by DHM-1

\begin{tabular}{lccccccccccc}
\hline${ }^{14} \mathrm{C}$ added as: & \multicolumn{10}{c}{$\%$ of ${ }^{14} \mathrm{C}$ added recovered as } \\
\cline { 2 - 12 } & $\mathrm{CH}_{\mathbf{4}}$ & $\mathrm{CO}$ & $\mathrm{CM}$ & $\mathrm{DCM}$ & $\mathrm{CS}_{\mathbf{2}}$ & $\mathrm{CF}$ & $\mathrm{CT}$ & other $^{b}$ & $\mathrm{CO}_{\mathbf{2}}$ & Soluble $^{c}$ & Loss $^{\boldsymbol{d}}$ \\
\hline $\mathrm{CT}$ & 0.1 & $\mathbf{1 4}$ & 0.3 & 0 & 5.2 & 2.2 & 0 & 0.1 & $\mathbf{5 1}$ & $\mathbf{2 7}$ & 0 \\
$\mathrm{CF}$ & 0.5 & $\mathbf{6 7}$ & 0 & 0 & 0 & 0.9 & 0.2 & 0.8 & 2.7 & $\mathbf{1 5}$ & $\mathbf{1 3}$ \\
\hline
\end{tabular}

${ }^{a}$ Numbers in bold represent the main products formed.

${ }^{b}$ Other volatile ${ }^{14} \mathrm{C}$-labeled compounds that were not identified.

${ }^{c 14} \mathrm{C}$-labeled compounds that remained after sparging samples under acidic conditions; HPLC analysis indicated the majority of this fraction consisted of organic acids (see text).

${ }^{d}$ Loss $=$ amount of ${ }^{14} \mathrm{C}$ added that was not accounted for in the other compounds or categories listed.

The ability of the DHM-1 enrichment culture to biodegrade CF concentrations above $500 \mathrm{mg} / \mathrm{L}$ was evaluated. Approximately $1000 \mathrm{mg} / \mathrm{L}$ (i.e., $900 \mu \mathrm{mol} / \mathrm{bottle}$ ) was transformed in 85 days and $2000 \mathrm{mg} / \mathrm{L}$ (i.e., $1800 \mu \mathrm{mol} /$ bottle) in 180 days (Figure 2). Accumulation of DCM and $\mathrm{CS}_{2}$ was negligible ( $<0.5$ and $1.0 \mu \mathrm{mol} / \mathrm{bottle}$, respectively). WC results indicated that diffusive loss of CF was minor. Activity on CF ceased at $4000 \mathrm{mg} / \mathrm{L}$ (i.e., $3600 \mu \mathrm{mol} /$ bottle), which is approximately $50 \%$ of the aqueous solubility of CF at $20^{\circ} \mathrm{C}$. Growth of DHM-1 on corn syrup, however, was not adversely affected by the high concentrations of CF. Protein concentrations increased to 89, 97 and $128 \mu \mathrm{g} / \mathrm{mL}$ for treatments that received 1000, 2000 and $4000 \mathrm{mg} / \mathrm{L}$ of $\mathrm{CF}$, respectively; this is similar to previously reported levels for DHM-1 in the absence of CF, and in the presence of CF at $500 \mathrm{mg} / \mathrm{L}$ (Shan et al. 2010a). Although growth of DHM-1 in the presence of CT or CFC11 was not monitored, an increase in the turbidity of the MSM a few days after inoculation suggested that DHM-1 also grows on corn syrup in the presence of $\mathrm{CT}$ and CFC-11.

Effect of $\mathrm{B}_{12}$ concentration and $\mathrm{pH}$ on $\mathrm{CF}$ biodegradation by DHM-1

Reducing the molar ratio of $\mathrm{B}_{12}$ added per mole of $\mathrm{CF}$ added from $0.03 \mathrm{~mol} \mathrm{~B}_{12}$ per mol of $\mathrm{CF}$ added to 0.01 resulted in a moderate decrease in the maximum $\mathrm{CF}$ transformation rate, while the rate fell more quickly below 0.01 (Figure 3). Fitting the data to equation 1 resulted in a $V_{\max }$ of $66 \pm 4.6 \mathrm{mg} \mathrm{CF} / \mathrm{L} / \mathrm{d}$ and a $B_{12} / K_{m}$ ratio of $0.0050 \pm 0.0010 \mathrm{~mol} \mathrm{~B} \mathrm{~B}_{12}$ per mol CF ( \pm values indicate $95 \%$ confidence intervals). Assuming a yield of
50-60 $\mathrm{mg}$ protein/L from the single dose of corn syrup added (Shan et al. 2010a), $V_{\max }$ can be normalized to approximately $1.2 \mathrm{mg} \mathrm{CF} / \mathrm{mg}$ protein/d.

Maximum CF biodegradation rates for DHM-1 increased with increasing pH from 5.0 to 7.7 (Figure 4). There appeared to be a plateau in the $\mathrm{pH}$ range from 6.4 to 7.3 , while the rate at $\mathrm{pH} 7.7$ almost doubled relative to that in the circumneutral $\mathrm{pH}$ region, reaching $50 \mathrm{mg} /$ L/d. The activity of DHM-1 diminished substantially below $\mathrm{pH} 6.0$ and ceased at $\mathrm{pH}$ of 5.0. Lag times (i.e., the time prior to the onset of a maximum rate) decreased as $\mathrm{pH}$ increased.

\section{Effect of DHM-1 inoculum level on CF biodegradation}

Biodegradation of CF proceeded at a high rate even at a DHM-1 inoculum level as low as $10^{-8}$ percent $(\mathrm{v} / \mathrm{v})$ (Figure 5, treatments A-E). The 5\% inoculum (v/v) corresponds to a protein concentration of approximately $5 \mathrm{mg} / \mathrm{L}$, so the $10^{-8}$ inoculum equates to approximately $10^{-8} \mathrm{mg} / \mathrm{L}$. Headspace monitoring continued until CF fell below the maximum contaminant level (MCL) for trihalomethanes $(80 \mu \mathrm{g} / \mathrm{L})$. At a $5 \%$ inoculum inoculum level, 23 days of incubation was required, while 39 days was required for the $10^{-8} \%$ inoculum level. Correspondingly, the maximum initial degradation rate was approximately twice as high at the highest inoculum $(30 \mathrm{mg} / \mathrm{L} / \mathrm{d})$ compared to the lowest $(17 \mathrm{mg} / \mathrm{L} / \mathrm{d})$. Accumulation of DCM and CM amounted to less than $0.6 \%$ of the CF consumed. Losses from uninoculated controls (treatments F-I) were comparatively minor. These results demonstrate the potential for DHM-1 to biodegrade high

Table 2 Fluoride mass balance from degradation of CFC-11 ${ }^{a}$

\begin{tabular}{|c|c|c|c|c|c|c|}
\hline Treatment & $\begin{array}{l}\text { No. of } \\
\text { bottles }\end{array}$ & $\begin{array}{l}\text { CFC-11 consumed } \\
(\mu \mathrm{mol} / \mathrm{bottle})\end{array}$ & $\begin{array}{c}\mathbf{F}^{-} \text {released } \\
(\mu \mathrm{mol} / \mathrm{bottle})\end{array}$ & $\begin{array}{c}\mathrm{CHCl}_{2} \mathrm{~F} \text { formed } \\
\text { ( } \mu \mathrm{mol} / \text { bottle) }\end{array}$ & $\begin{array}{c}\mathrm{CH}_{2} \mathrm{CIF} \text { formed } \\
\text { ( } \mu \mathrm{mol} / \text { bottle })\end{array}$ & $\mathrm{F}^{-}$recovery $(\%)^{b}$ \\
\hline$\overline{\mathrm{DHM}}-1+\mathrm{CS}+\mathrm{B}_{12}^{\mathrm{C}}$ & 14 & $61.6 \pm 2.1^{d}$ & $57.4 \pm 4.6$ & $3.1 \pm 1.0$ & $0.8 \pm 0.9$ & $99.5 \pm 8.0$ \\
\hline $\mathrm{DHM}-1+\mathrm{CS}^{e}$ & 3 & $1.8 \pm 1.2$ & 0 & $0.9 \pm 0.1$ & $0.09 \pm 0.04$ & - \\
\hline$M S M+B_{12}$ & 6 & $27.1 \pm 2.7$ & $17.7 \pm 5.0$ & $0.5 \pm 0.3$ & $0.06 \pm 0.05$ & $68.0 \pm 10.1$ \\
\hline MSM & 6 & $1.5 \pm 3.0$ & 0 & $0.06 \pm 0.03$ & $0.2 \pm 0.3$ & - \\
\hline
\end{tabular}

${ }^{a}$ Headspace monitoring results are presented in the Supporting Information.

${ }^{b}$ Calculated according to equation S-1 in Additional file 1.

Includes three bottles that also received $500 \mathrm{mg} / \mathrm{L} \mathrm{CF}$, which had no effect of the $\mathrm{F}^{-}$mass balance, $\mathrm{CS}=$ corn syrup.

${ }^{d} \pm=$ Standard deviation.

${ }^{e}$ Inoculum was washed in fresh MSM to avoid carryover of $B_{12}$. 


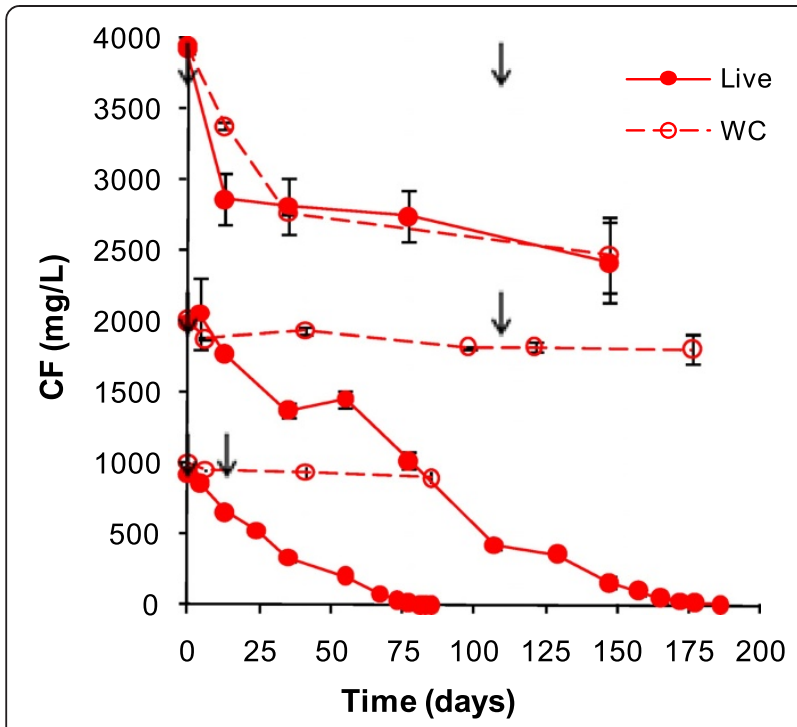

Figure 2 CF biodegradation by DHM-1 in MSM with one dose of $B_{12}(a t t=0)$ and two doses of corn syrup (arrows); WC = water control. Error bars represent the data range for duplicate bottles; when not visible, the bars are smaller than the symbols.

concentrations of $\mathrm{CF}$ even at a low initial cell density, which is an essential characteristic for use in bioaugmentation.

\section{Biodegradation of mixtures of halomethanes}

In the presence of $12 \mathrm{mg} / \mathrm{L} \mathrm{CT}(13 \mu \mathrm{mol} / \mathrm{bottle})$ and $512 \mathrm{mg} / \mathrm{L}$ CF $(463 \mu \mathrm{mol} /$ bottle $)$, DHM-1 biodegraded both halomethanes simultaneously, with no apparent effect of $\mathrm{CT}$ on $\mathrm{CF}$ or vice versa (Figure 6a). A low amount of $\mathrm{CS}_{2}(5.2 \mu \mathrm{mol} /$ bottle $)$ accumulated, accounting for $1 \%$ of the $\mathrm{CT}+\mathrm{CF}$ transformed. Formation of DCM

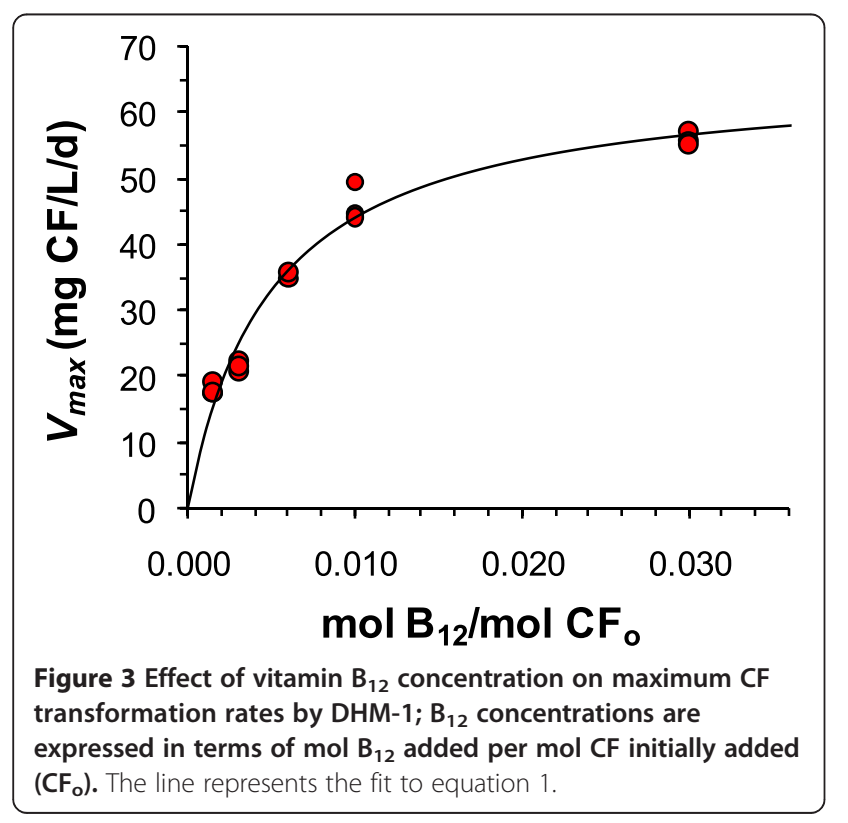

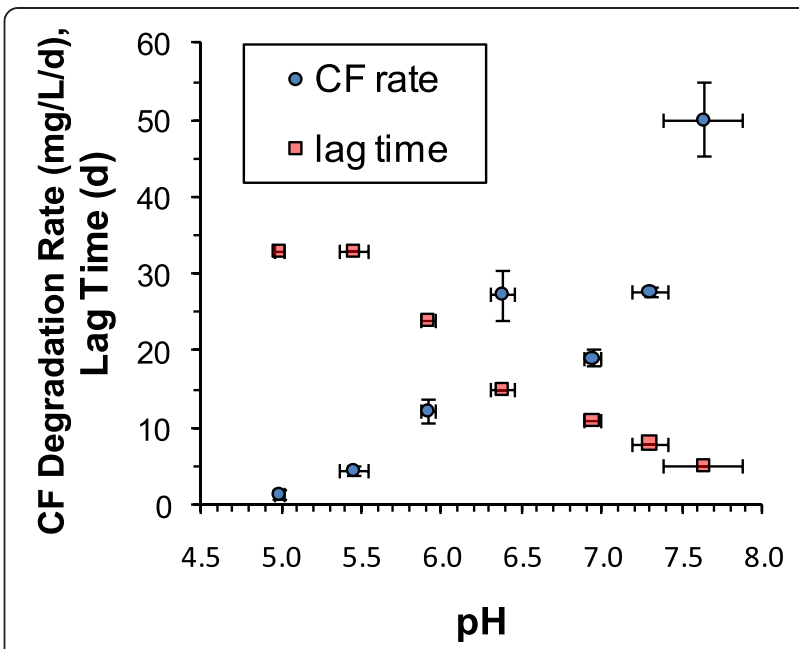

Figure 4 Impact of $\mathrm{pH}$ on biodegradation rates for CF by DHM-1 and the length of the lag phase prior to the onset of biodegradation. Error bars in both directions indicate the 95\% confidence interval, based on results from triplicate bottles at each $\mathrm{pH}$.

(0.6 $\mu \mathrm{mol} /$ bottle) was negligible. With a mixture of $23 \mathrm{mg} / \mathrm{L} \mathrm{CFC}-11$ (55 $\mu \mathrm{mol} /$ bottle) and $509 \mathrm{mg} / \mathrm{L} \mathrm{CF}$ (461 $\mu \mathrm{mol} /$ bottle), DHM-1 biodegraded CFC-11 faster than when CFC-11 was added individually (Figure $1 \mathrm{~b}$ versus $6 \mathrm{~b}$ ), possibly related to changes in membrane fluidity or homeoviscous and homeophasic adaptation during growth in the presence of a high concentration of CF (Shan et al. 2010a). In contrast, CF transformation was inhibited by the presence of CFC-11; CF transformation did not begin until the concentration of CFC-11 dropped to $6 \mathrm{mg} / \mathrm{L}(14 \mu \mathrm{mol} /$ bottle $)$ on day 18 . Minor amounts of $\mathrm{CS}_{2}, \mathrm{DCM}$ and HCFC-21 accumulated in comparison to the amount of halomethanes removed. With a mixture of $16 \mathrm{mg} / \mathrm{L} \mathrm{CT}(17 \mu \mathrm{mol} /$ bottle $)$ and $24 \mathrm{mg} / \mathrm{L} \mathrm{CFC}-11$ (57 $\mu \mathrm{mol} /$ bottle), CT was consumed in 10 days; following a lag phase of approximately 10 days, CFC-11 was consumed by day 47 (Figure 6c). These patterns are similar to what occurred with the individual compounds, indicating no apparent interaction between $\mathrm{CT}$ and CFC-11. The combination of CT and CFC-11 resulted in more $\mathrm{CS}_{2}$ accumulation than the other twocomponent mixtures, accounting for $7.7 \%$ of the $\mathrm{CT}$ and CFC-11 transformed. Formation of HCFC-21 was also slightly higher than in the mixture of $\mathrm{CFC}-11$ and $\mathrm{CF}$, while formation of DCM was negligible.

When CT, CFC-11, and CF (11, 24, and $500 \mathrm{mg} / \mathrm{L}$, respectively) were added at the same time, the pattern of transformation was similar to the two-component mixtures. CT $(12 \mu \mathrm{mol} /$ bottle) transformation was completed first, followed by CFC-11 $(57 \mu \mathrm{mol} / \mathrm{bottle})$ and then CF $(456 \mu \mathrm{mol} /$ bottle) (Figure $7 \mathrm{~d})$. One difference between the live treatments shown in Figures 6 and $7 d$ is 


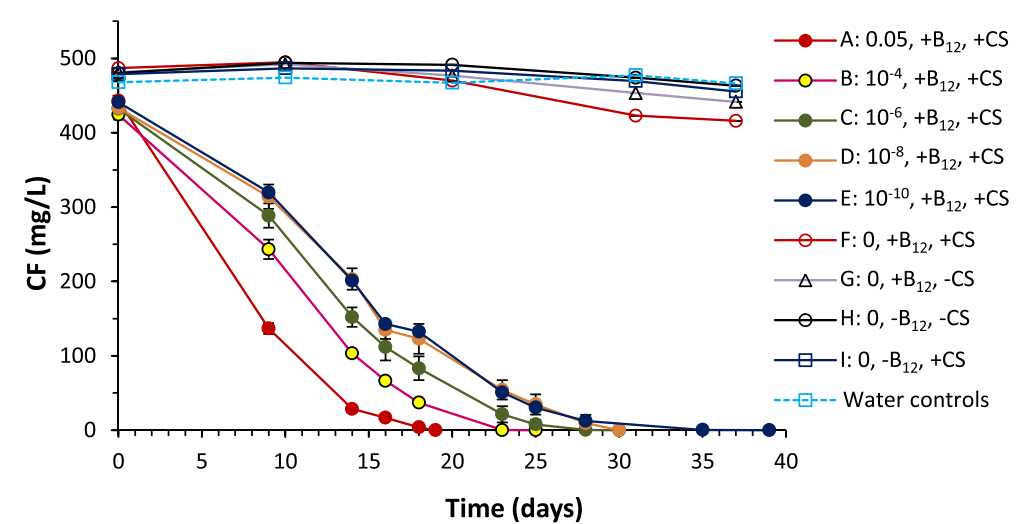

Figure 5 CF degradation with different inoculum levels of DHM-1 (percent by volume, indicated by the number after the treatment letter). Treatments A through E contained DHM-1, corn syrup (CS) and $B_{12}$ (3 mol\% of CF). Treatments $F$ through I were abiotic controls. Error bars show standard deviations of triplicate bottles.

the pattern of $\mathrm{B}_{12}$ addition. With the two-component mixtures (Figure 6), $\mathrm{B}_{12}$ was added only at the start. With the three-component mixture (Figure $7 \mathrm{~d}$ ), the same molar ratio of $B_{12}$ was applied, although the additions were timed to coincide with the beginning of transformation of each compound. Accumulation of $\mathrm{CS}_{2}, \mathrm{DCM}$, CM, HCFC-21, and HCFC-31 was negligible. Results for controls are shown in Figure 7, panels a, b and c. Nearly complete transformation of CT occurred by day 113 in the media control and $\mathrm{AC}$, versus no significant losses from the WC. Approximately 33\% and 11\% of CFC- 11 was removed in the autoclaved and media controls, respectively, while loss of CFC-11 in WC was minor. Losses of $\mathrm{CF}$ in all of the controls were minor. These results demonstrated that transformation of $\mathrm{CF}$ was exclusively a biotic process, while abiotic processes contributed to transformation of CT and CFC-11. However, transformation of CT and CFC-11 was considerably faster in the presence of live cells, and DHM-1 was able to achieve complete transformation of a mixture of CT, CFC-11 and $\mathrm{CF}$ at high initial concentrations in less than four months in MSM.

\section{Discussion}

The feasibility of using bioremediation to clean up halogenated solvents in the vicinity of nonaqueous phase liquids depends in part on the ability of microbes to grow in the presence of contaminant concentrations that approach their aqueous solubility limit. The results of this study indicate that the DHM-1 enrichment culture grows in the presence of at least $4000 \mathrm{mg} / \mathrm{L} \mathrm{CF}$, approximately one half its aqueous solubility, and the culture retains its ability to biodegrade CF at $2000 \mathrm{mg} / \mathrm{L}$. When transforming $500 \mathrm{mg} / \mathrm{L}$ of CF, the two Pantoea spp. isolated from DHM-1 adapted their growth by alteration of their membrane fluidity or homeoviscous and homeophasic adaptation (Shan et al. 2010a). A similar response at the higher CF concentrations evaluated in this study seems likely. Tolerance of high concentrations of halogenated compounds appears to be a characteristic of Enterobacter species (Sharma and McCarty 1996), which are closely related to Pantoea (Shan et al. 2010a). Several bioaugmentation cultures that are enriched in Dehalococcoides and used to treat chlorinated ethenes also possess the ability to grow at the high solvent concentrations found near nonaqueous phase liquids (ESTCP 2005).

DHM-1 was effective in transforming CT $(\sim 11 \mathrm{mg} / \mathrm{L})$ and CFC-11 ( 24 mg/L) as well as CF. Based on experiments with ${ }^{14} \mathrm{C}$-labeled $\mathrm{CT}$ and $\mathrm{CF}$, the primary transformation products are environmentally benign $\left(\mathrm{CO}_{2}\right.$, $\mathrm{CO}$ and organic acids). Similar results were obtained with DHM-1 when it was in an earlier stage of development (Shan et al. 2010b). Although $\left[{ }^{14} \mathrm{C}\right] \mathrm{CFC}-11$ was not used in this study, the majority of the CFC-11 consumed was accounted for as fluoride and no volatile products were detected, suggesting the primary transformation products were nonhazardous. DHM-1 did not produce significant levels of DCM and CM from CT and CF. DCM and CM are not necessarily problematic, since both are readily fermentable (Mägli et al. 1998). In contrast, little is known about the anaerobic biodegradability of HCFC-21 and HCFC-31; if significant levels are formed from CFC-11, it is unclear how quickly they can be degraded. Preliminary experiments indicate an anaerobic culture that grows on DCM as its sole substrate was unable to utilize HCFC-31 (Shan 2009).

Halomethanes are often found in mixtures at hazardous waste sites. DHM-1 was effective in transforming mixtures of CT, CFC-11 and CF. Consistent with general expectations for halomethanes (Wackett et al. 1992), CT was transformed first, followed by CFC-11 and then CF. The inhibitory effect of CFC- 11 on CF is a potential concern, since the average rate of CFC- 11 transformation by DHM-1 was approximately 40-fold slower than CF. 


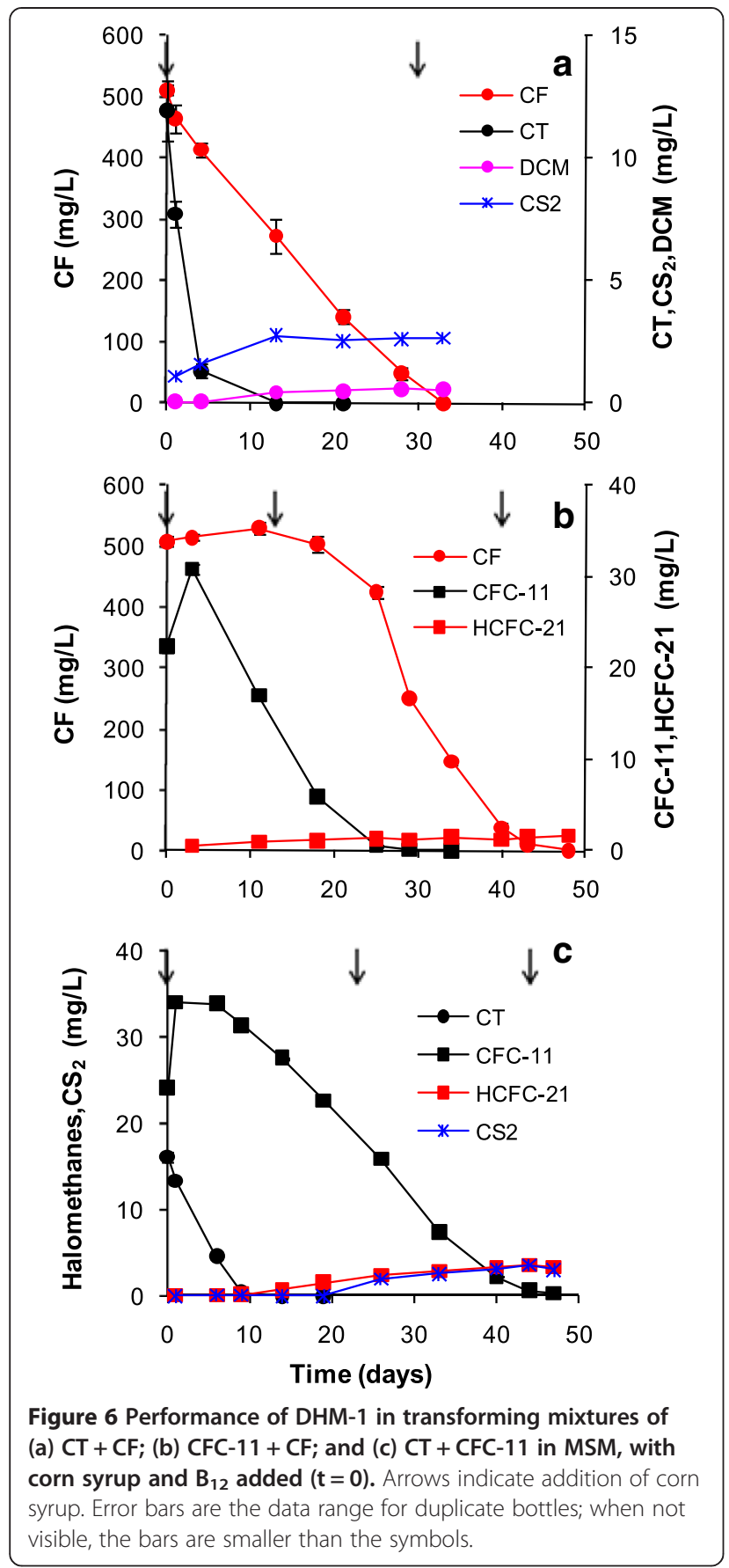

An important consideration for cultures used in bioaugmentation is the required inoculum level. For chlorinated ethenes, a commonly used target is $10^{7}$ cells/ $\mathrm{L}$ of Dehalococcoides (ESTCP 2010). Assuming a unit mass of $1.6 \times 10^{-14} \mathrm{~g} /$ cell (Cupples et al. 2003) and one half of the cell mass is protein, this equates to an inoculum of $8 \times 10^{-5} \mathrm{mg} / \mathrm{L}$ protein. DHM-1 was able to biodegrade $500 \mathrm{mg} / \mathrm{L}$ of $\mathrm{CF}$ at a high rate with a volumetric addition as low as $10^{-8}$ percent; this equates to a

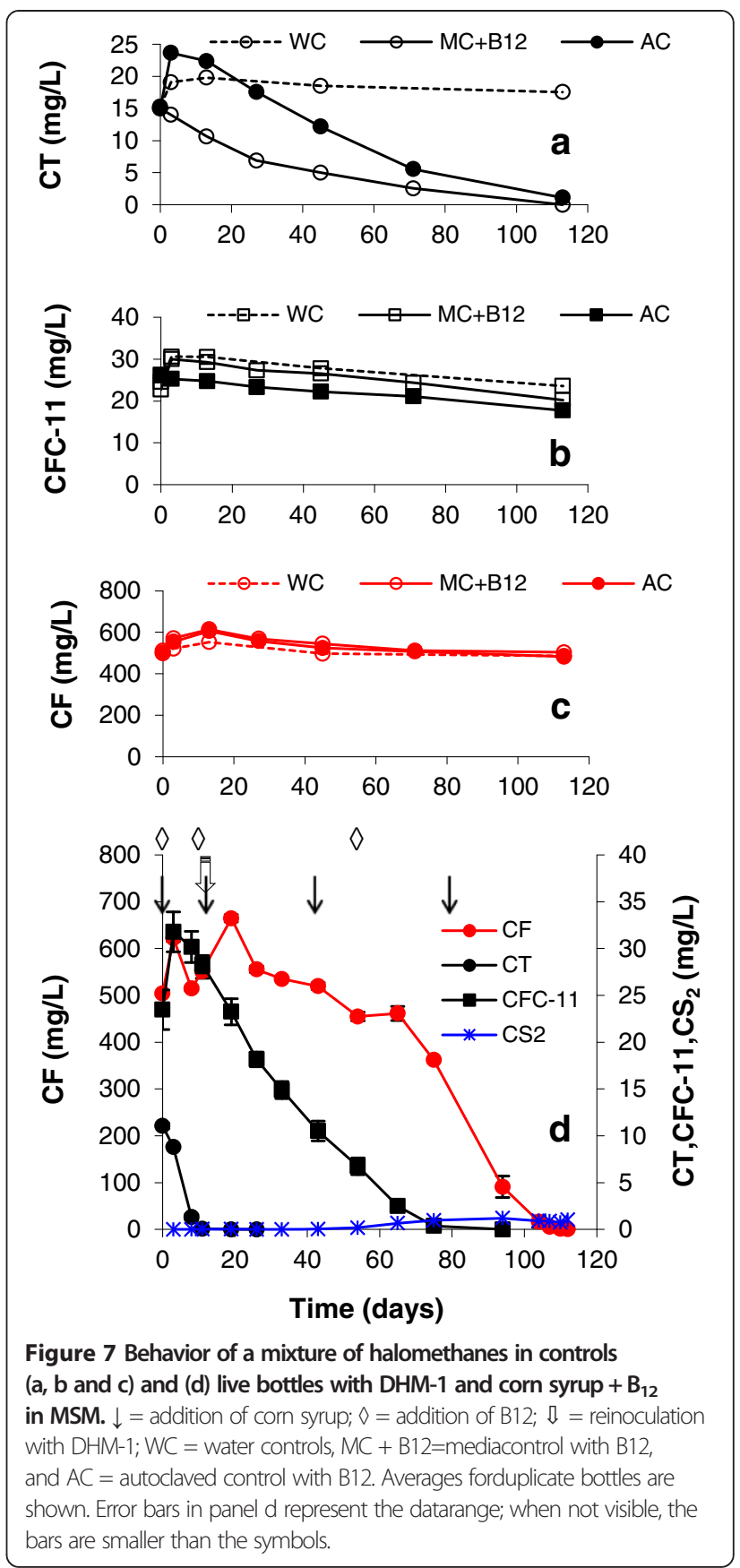

concentration of $10^{-8} \mathrm{mg} / \mathrm{L}$ protein, several orders of magnitude lower than the target for Dehalococcoides. This suggests that achieving an adequate inoculum in situ will not be problematic.

The catalytic degradation of halogenated compounds by $B_{12}$ and other transition metal coenzymes under low redox conditions has long been recognized (e.g., Gantzer and Wackett 1991; Wackett et al. 1992). One of the concerns with using $\mathrm{B}_{12}$ along with DHM-1 for bioaugmentation is the culture's relatively high requirement for $B_{12}$. 
In a previous study we used a $\mathrm{B}_{12}$ molar dose of $3 \%$, i.e., $0.03 \mathrm{~mol} \mathrm{~B}_{12}$ per mol CF (Shan et al. 2010a). Varying the $\mathrm{B}_{12}$ dose in this study indicated a half saturation value of $0.005 \mathrm{~mol} \mathrm{~B}_{12} / \mathrm{mol} \mathrm{CF}$. A ratio $0.005 \mathrm{~mol} \mathrm{~B}_{12} / \mathrm{mol} \mathrm{CT}$ also significantly improved the rate of CT degradation in a methanogenic sludge consortium, at a CT concentration of $15.4 \mathrm{mg} / \mathrm{L}$ (Guerrero-Barajas and Field 2005). Nevertheless, for halomethane concentrations in the hundreds of $\mathrm{mg} / \mathrm{L}$, the $\mathrm{B}_{12}$ required by DHM- 1 is several orders of magnitude higher than what is needed to grow Dehalococcoides (He et al. 2007), for which $\mathrm{B}_{12}$ functions as a cofactor for reductive dehalogenases (Schipp et al. 2013).

Aquifer $\mathrm{pH}$ is a significant concern for bioaugmentation, since many cultures lose effectiveness at $\mathrm{pH}$ levels below 6 or above 8 . The highest $\mathrm{pH}$ evaluated in this study was 7.6 , which yielded a higher rate than in the circumneutral pH region (6.3-7.3; Figure 4). CF biodegradation rates decreased significantly below 6.0 and activity essentially ceased at $\mathrm{pH}$ 5.0. This is similar to the behavior of many Dehalococcoides enrichment cultures (ESTCP 2005; Vainberg et al. 2009). The difficulties associated with adjusting aquifer $\mathrm{pH}$ include non-homogenous distribution of the buffering agent and the potential for clogging due to precipitation when $\mathrm{pH}$ is increased.

For contaminant plumes with high concentrations of halomethanes that are not undergoing natural attenuation, the options for bioremediation are limited. The benefits of using a culture such as DHM-1 include its high rate of $\mathrm{CF}$ transformation; its ability to transform mixtures of CT, CF, and CFC-11; the conversion of these halomethanes to environmentally benign products; its growth on an inexpensive primary substrate (corn syrup); and its ability to grow in the presence of CF at levels at least as high as $4000 \mathrm{mg} / \mathrm{L}$. The culture also retains its ability to anaerobically transform CF after exposure to air for as long as one day (Additional file 1: Figure S3). Further studies are needed to validate the use of DHM-1 under field conditions, and to determine if lower cost formulations of $\mathrm{B}_{12}$ can be developed, e.g., using the fermentation product from cultures that synthesize $B_{12}$ with a lesser degree of purification.

\section{Additional file}

Additional file 1: Fluoride Measurements; Abiotic Controls Figure S1. Soluble Products from Biodegradation of CT and CF Table S1. Fluoride Mass Balance Figure S2. and Ability of DHM-1 to Tolerate Exposure to Oxygen Figure S3.

\section{Competing interests}

The authors declare that they have no competing interests.

\section{Authors' contributions}

HS carried out the experiments to evaluate biodegradation of CT, CF, and

CFC-11, individually and in mixtures, as well as the biodegradability of CF at concentrations above $500 \mathrm{mg} / \mathrm{L}$. HW and RY performed experiments on the effect of $\mathrm{pH}$ and $\mathrm{B}_{12}$ on the biodegradation rate for $\mathrm{CF}$, including the parameter estimation for equation 1. PJ carried out experiments to determine the mass balance on fluoride during biodegradation of CFC-11 and the effect of inoculum level on the rate of CF biodegradation. DLF conceived of the study, and participated in its design and coordination and helped to draft the manuscript. All authors read and approved the final manuscript.

\section{Acknowledgments}

HS, HW, RY and PJ were supported by teaching assistantships from Clemson University while this research was conducted.

\section{Author details}

${ }^{1}$ PeroxyChem Environmental Solutions (East Asia), Room 5B16, West Wing, Hanwei Plaza, 7 Guanghua Road, Chaoyang District, Beijing 100004, China. ${ }^{2}$ Department of Environmental Engineering and Earth Sciences, Clemson University, Box 340919, 29634-0919 Clemson, SC, USA.

Received: 8 May 2014 Accepted: 14 May 2014

Published online: 14 June 2014

\section{References}

ATSDR (2013) The ATSDR 2011 Substance Priority List. Agency for Toxic Substances and Disease Registry. http://www.atsdr.cdc.gov/spl

Bagley DM, Lalonde M, Kaseros V, Stasiuk KE, Sleep BE (2000) Acclimation of anaerobic systems to biodegrade tetrachloroethene in the presence of carbon tetrachloride and chloroform. Wat Res 34(1):171-178

Becker JG, Freedman DL (1994) Use of cyanocobalamin to enhance anaerobic biodegradation of chloroform. Environ Sci Technol 28(11):1942-1949

Coleman NV, Mattes TE, Gossett JM, Spain JC (2002) Biodegradation of cis-dichloroethene as the sole carbon source by a $\beta$-proteobacterium. Appl Environ Microbiol 68(6):2726-2730

Conrad R, Klose M (1999) Anaerobic conversion of carbon dioxide to methane, acetate and propionate on washed rice roots. FEMS Microbiol Ecol 30(2):147-155

Cupples AM, Spormann AM, McCarty PL (2003) Growth of a Dehalococcoides-like microorganism on vinyl chloride and cis-dichloroethene as electron acceptors as determined by competitive PCR. Appl Environ Microbiol 69(2):953-959

ESTCP (Environmental Security Technology Certification Program) (2005) Bioaugmentation for Remediation of Chlorinated Solvents: Technology Development, Status and Research Needs. http://www.clu-in.org/download/ remed/Bioaug2005.pdf

ESTCP (Environmental Security Technology Certification Program) (2010) Bioaugmentation for Groundwater Remediation. Cost and Performance Report \#ER-0515. https://www.clu-in.org/download/techfocus/biochlor/ DNAPL-ER-0515-C\&P.pdf

Freedman DL, Gossett JM (1991) Biodegradation of dichloromethane and its utilization as a growth substrate under methanogenic conditions. Appl Environ Microbiol 57(10):2847-2857

Freedman DL, Lasecki M, Hashsham S, Scholze R (1995) Accelerated biotransformation of carbon tetrachloride and chloroform by sulfatereducing enrichment cultures. In: Hinchee RE, Leeson A, Semprini L (ed) Bioremediation of Chlorinated Solvents. Bioremediation, vol 4. Battelle, Columbus, OH, pp 123-138

Gantzer CJ, Wackett LP (1991) Reductive dechlorination catalyzed by bacterial transition-metal coenzymes. Environ Sci Technol 25(4):715-722

Grostern A, Duhamel M, Dworatzek S, Edwards EA (2010) Chloroform respiration to dichloromethane by a Dehalobacter population. Environ Microbiol 12(4):1053-1060

Guerrero-Barajas C, Field JA (2005) Enhancement of anaerobic carbon tetrachloride biotransformation in methanogenic sludge with redox active vitamins. Biodegradation 16(3):215-228

He J, Holmes VF, Lee PKH, Alvarez-Cohen L (2007) Influence of vitamin $B_{12}$ and cocultures on the growth of Dehalococcoides isolates in defined medium. Appl Environ Microbiol 73(9):2847-2853

Justicia-Leon SD, Ritalahti KM, Mack EE, Löffler FE (2012) Dichloromethane fermentation by a Dehalobacter sp. in an enrichment culture derived from pristine river sediment. Appl Environ Microbiol 78(4):1288-1291

Krone UE, Thauer RK (1992) Dehalogenation of trichlorofluoromethane (CFC-11) by Methanosarcina barkeri. FEMS Microbiol Lett 90:201-204 
Lee M, Low A, Zemb O, Koenig J, Michaelsen A, Manefield M (2012) Complete chloroform dechlorination by organochlorine respiration and fermentation. Environ Microbiol 14(4):883-894

Lewis TA, Paszczynski A, Gordon-Wylie SW, Jeedigunta S, Lee C-H, Crawford RL (2001) Carbon tetrachloride dechlorination by the bacterial transition metal chelator pyridine-2,6-bis (thiocarboxylic acid). Environ Sci Technol 35(3):552-559

Mägli A, Messmer M, Leisinger T (1998) Metabolism of dichloromethane by the strict anaerobe Dehalobacterium formicoaceticum. Appl Environ Microbiol 64(2):646-650

Schipp CJ, Marco-Urrea E, Kublik A, Seifert J, Adrian L (2013) Organic cofactors in the metabolism of Dehalococcoides mccartyi strains. Philos Trans R Soc B 368(1616). doi:10.1098/rstb.2012.0321

Shan H (2009) Development of Strategies for Enhanced In Situ Bioremediation of High Concentrations of Halogenated Methanes. Ph.D. Thesis, Clemson University. Clemson University, Clemson, SC

Shan H, Kurtz HD, Jr, Mykytczuk N, Trevors JT, Freedman DL (2010a) Anaerobic biotransformation of high concentrations of chloroform by an enrichment culture and two bacterial isolates. Appl Environ Microbiol 76(19):6463-6469

Shan H, Kurtz HD, Jr, Freedman DL (2010b) Evaluation of strategies for anaerobic bioremediation of high concentrations of halomethanes. Wat Res 44:1317-1328

Sharma PK, McCarty PL (1996) Isolation and characterization of a facultatively aerobic bacterium that reductively dechlorinates tetrachloroethene to cis-1,2-dichloroethene. Appl Environ Microbiol 62:761-765

Vainberg S, Condee C, Steffan R (2009) Large-scale production of bacterial consortia for remediation of chlorinated solvent-contaminated groundwater. J Indus Microbiol Biotechnol 36(9):1189-1197

Wackett LP, Logan MSP, Blocki FA, Bao-li C (1992) A mechanistic perspective on bacterial metabolism of chlorinated methanes. Biodegradation 3:19-36

doi:10.1186/s13568-014-0048-5

Cite this article as: Shan et al: Biodegradation of high concentrations of halomethanes by a fermentative enrichment culture. AMB Express 2014 4:48.

\section{Submit your manuscript to a SpringerOpen ${ }^{\circ}$ journal and benefit from:}

- Convenient online submission

- Rigorous peer review

- Immediate publication on acceptance

- Open access: articles freely available online

- High visibility within the field

- Retaining the copyright to your article

Submit your next manuscript at $\gg$ springeropen.com 